\title{
Relationship Between Apple Fruit Epicuticular Wax and Growth of Peltaster fructicola and Leptodontidium elatius, Two Fungi that Cause Sooty Blotch Disease
}

\author{
Robert D. Belding, Former Graduate Student, Department of Horticultural Science; Turner B. Sutton, Department \\ of Plant Pathology; and Sylvia M. Blankenship and Eric Young, Department of Horticultural Science, North \\ Carolina State University, Raleigh, NC 27695-7609
}

\begin{abstract}
Belding, R. D., Sutton, T. B., Blankenship, S. M., and Young, E. 2000. Relationship between apple fruit epicuticular wax and growth of Peltaster fructicola and Leptodontidium elatius, two fungi that cause sooty blotch disease. Plant Dis. 84:767-772.

Sooty blotch severity varied among apple cultivars or selections surveyed in 1989 and 1992 . No mycelial growth was observed on russetted areas of the cuticle that are considered impermeable. Ursolic acid and n-alkanes were the most prominent components of the epicuticular waxes of the cultivars or selections evaluated. Although there were differences in the relative proportions of these compounds among the cultivars, the differences were not related to the severity of sooty blotch. Peltaster fructicola and Leptodontidium elatius were grown on compounds that comprise the epicuticular wax of the fruit to determine if one or more of these were needed for growth. The fungi did not grow on any of the five major components of the epicuticular wax unless dilute apple juice was included. Scanning electron microscopy studies showed that mycelia of $P$. fructicola grew on the surface of the wax and did not appear to degrade it. Our studies support the hypothesis that $P$. fructicola and $L$. elatius fungi are epiphytes and obtain their nutrients not from components of the cuticle, but more likely from fruit leachates.
\end{abstract}

Peltaster fructicola Johnson, Sutton et Hodges, and Leptodontidium elatius (G. Mangenot) De Hoog are two major components of the sooty blotch complex of apple fruit (Malus $\times$ domestica Borkh.). Other organisms contribute to sooty blotch disease, but these two were chosen to represent two extremes in growth forms. $P$. fructicola and L. elatius do not penetrate the cuticle of the fruit (13); however, the presence of mycelial growth on the surface of fruit renders them unsightly and unacceptable for the fresh fruit market. In the southeastern United States, sooty blotch and flyspeck (caused by Zygophiala jamaicensis E. Mason; teleomorph, Schizothyrium pomi) result in losses of 5 to $10 \%$ of the apple crop annually even with rigorous use of fungicide cover sprays (19,

Corresponding author: R. D. Belding E-mail: Belding@aescop.Rutgers.edu

Current address of senior author: R. D. Belding, Rutgers Agricultural Research and Extension Center, 121 Northville Road, Bridgeton, NJ 08302 .

This research was funded by the North Carolina Agricultural Research Service (NCARS), Raleigh 27695-7643. Use of trade names in this publication does not imply endorsement by the NCARS of products named nor criticism of similar ones not mentioned.

Accepted for publication 21 March 2000.

Publication no. D-2000-0425-01R

(C) 2000 The American Phytopathological Society
T. Sutton unpublished data). In an average year, without the benefit of fungicides, sooty blotch and flyspeck affect close to $100 \%$ of the apples produced in the Southeast.

Growth of sooty blotch fungi is restricted to the surface of fruit and penetration through the cuticle into the epidermal cells does not occur; therefore, all nutritional needs of the fungi must be present on the fruit's surface in order to support their growth and reproduction. Epiphytic fungal growth can only be supported nutritionally from three sources: (i) components of the surface (i.e., cuticular wax or cutin); (ii) external sources: materials adhering to the surface; or (iii) internal leachates: exuded materials that are dependent on the permeability of the cuticle. Nasu and Kunoh (26) observed that Z. jamaicensis also did not penetrate apple cuticles but, when observed with scanning electron microscopy (SEM), waxy crystals appeared dissolved along the hyphae.

Epicuticular wax quantity and composition vary consistently among cultivars (5). Components of apple fruit epicuticular wax include two main compounds, the largest a triterpenoid known as ursolic acid, and a 29-carbon n-alkane, nonacosane comprising 44 and $26 \%$ of the surface wax, respectively (5). Minor components of the epicuticular wax ranging from 0.2 to $12.5 \%$ of the wax are homologs of nonacosane, such as ketones, aldehydes, and primary and secondary alcohols. Belding (5) distinguished 18 wax compounds of the apple surface, 14 of which accounted for
$96 \%$ of the total extractable epicuticular wax.

Epicuticular waxes have been shown to protect plants from fungal infection. Martin et al. (23) isolated a fungistatic component of apple leaf wax that suppressed germination of powdery mildew (Sphaerotheca pannosa) conidia. This ether-soluble component was transferred onto susceptible broad bean leaves where it entirely suppressed formation of necrotic lesions caused by Botrytis fabae. Major et al. (20) found an aldehyde, $\propto$-hexanol, present at $75 \mu \mathrm{g} /$ liter in the cuticle of Ginkgo (Ginkgo biloba L.), which was lethal to conidia of Monilinia fructicola. Adams et al. (1) showed that fungus infection pegs of $\mathrm{Al}$ ternaria solani, Botrytis allii, Glomerella, and Monilinia fructicola were inhibited when grown in contact with ginkgo cuticles. Similarly, Johnston and Sproston (14) found that soluble cuticular wax components of cherry leaves reduced germination of conidia and inhibited germ tube growth of Stemphylium sarcinaeforme. Other studies have shown that cuticular waxes are associated with resistance of rose leaves to the germination of powdery mildew conidia (3), Eucalyptus camaldulensis to Phaeoseptorea eucalypti (11), and beetroot (Beta vulgaris L.) to Botrytis cinerea (6). In the study of beetroot (6), inhibitors of wax development, trichloroacetic acid, or thiocarbamates resulted in reduced wax and an increased germination of $B$. cinerea in a dose dependent manner.

The morphology and thickness of the surface wax varies among apple cultivars, and morphology is believed to be dependent on the chemical composition of the cultivar $(12,24)$. The inherent chemical and physical properties rather than the properties of the underlying cuticular membrane influence the crystalline structure of epicuticular wax. This was demonstrated by Jeffree et al. (12) and McWhorter et al. (25), who observed the ultrastructure of recrystallized wax from several species by SEM and found that it was similar to the wax on the intact plant. At the same time, thickness and texture of the epicuticular wax also can be affected by environmental factors such as relative humidity $(\mathrm{RH})$, soil moisture, sunlight, and temperature $(4,27)$.

The morphology, arrangement, and density of crystals and hydrophobicity of the wax components determine the relative adhesion of water, pesticides, fungal 
spores, and other airborne deposits. The morphology of pecan leaf surface was found responsible for the retention or the erosion rate of the externally deposited exudation of aphids which result in sooty mold growth (29). Cultivar differences in surface texture were cited for being the causal factor in observed differences in susceptibility to sooty mold.

Deposition of water-borne pathogen spores is dependent upon both the ability of the cuticle to accept water and the ease with which the spores are wetted $(7,11)$. Some agricultural surfactants and chemicals actually inhibit development of epicuticular waxes and degrade the structure of the wax crystals $(9,21)$. When the ultrastructure is degraded, wettability increases, allowing liquids to adhere and spread more easily. The waxy bloom of grape berries (Vitis vinifera L. cv. Thompson Seedless) help protect them from infection by $B$. cinerea. When the wax structure was damaged due to the use of an agricultural surfactant, the susceptibility of the berry to infection by $B$. cinerea increased (22).

A preliminary survey of apple cultivars for the severity of sooty blotch revealed that the disease was more severe on some cultivars than others (T. Sutton, unpublished data). Sooty blotch fungi do not penetrate the cuticle; therefore, we hypothesized that differences in severity might be related to the differences in the waxy components of the apple cuticles. Therefore, the objectives of this study were to determine the ability of $P$. fructicola and L. elatius to utilize one or more components of the epicuticular wax of apple fruit as a carbon source for growth and development and to identify epicuticular wax components that might be useful as an indicator of resistance.

\section{MATERIALS AND METHODS}

Survey of sooty blotch severity among cultivars. Estimates of the disease severity and wax components were made in 1989 on six cultivars of apples, planted in 1982, in a replicated cultivar trial at North Carolina State University, Research Unit 2, Raleigh. Trees of Sundale Spur, Lys Golden, Pure Gold, Silverspur Red Delicious, Starkspur Supreme, and Starkrimson were used and 15 single fruit from each of the three tree replications were evaluated for the severity of sooty blotch, flyspeck, and russet at harvest on 24 August. Disease severity and russet were visually estimated as percentage of surface area covered. Disease severity data were collected and wax was extracted from the same fruit; however, in 1989, the data on each fruit was not tracked to allow direct comparison of disease severity and wax composition. Means of each were reported. Data from 1992 were collected to allow direct comparison of disease severity to wax composition. Fruit diameters were measured and used to estimate surface area covered.
In 1992, fruit were obtained from the Mountain Horticultural Crops Research Station in Fletcher, NC. Twenty-four fruit were arbitrarily selected at harvest on 26 August from the five cultivars or selections: Smoothie Golden Delicious, Coop17, Liberty, NY65707-19, and NY6135622. Severity of sooty blotch, flyspeck, and russet were determined as previously described.

In 1989, fruit surface area, used to calculate the amount of wax on a per unit basis, was estimated using fruit diameter and was calculated based on the area of a sphere of that diameter. In 1992, fruit volume was determined by first submerging fruit in water and weighing water displaced from the overflow beaker. The volume was first mathematically converted into the diameter of a sphere of that volume. Finally, surface area of a sphere was estimated from that diameter. Apple fruit surface area, when estimated from volume, was a more accurate than estimates from measured diameters (5).

Determination of the components of the epicuticular wax. The epicuticular wax was extracted from 45 fruit of each cultivar collected in 1989 and 24 fruit in 1992. From the 45 samples collected in 1989 from each cultivar, five samples were pooled and analyzed for wax composition, resulting in a total of three composite wax samples of five fruit each per tree times three trees per cultivar. In 1992, there were 24 random fruit from the available trees, and 12 samples were analyzed for wax composition. Each fruit was extracted using three successive 30-s dips in fresh chloroform. Extracts were pooled and the chloroform was removed. Waxes were transferred into preweighed vials, dried for $72 \mathrm{~h}$ over $\mathrm{CaSO}_{4}$, and the wax weight was recorded. Wax samples were stored at $-17^{\circ} \mathrm{C}$ without oxygen for determination of components with gas liquid chromatography (GLC).

Preparation of wax for analysis. The gas chromatography (GC) method used in this study was adapted from Lawrence et al. (18). A wax sample (1 mg) from each fruit received esterification with diazomethane. The wax sample was redissolved in $1 \mathrm{ml}$ of heptane:ether:methanol (10:10:1). Diazomethane gas was generated by the addition of $0.2 \mathrm{~g}$ of n-methyl-nnitroso-p-toluenesulfonamide to a tube containing $3 \mathrm{ml}$ of $37 \%$ potassium hydroxide, $2 \mathrm{ml}$ of 2-(ethoxy-ethoxy ethanol), and $2 \mathrm{ml}$ of ether in a steady stream of nitrogen saturated with ether. The diazomethane in gaseous form was then bubbled directly through the sample for $2 \mathrm{~min}$. The reaction was judged complete when the sample attained a persistent yellow color.

Silylation was achieved by adding $75 \mu \mathrm{l}$ of bis-(trimethylsilyl)-trifluoroacetamide (BSTFA) and $25 \mu \mathrm{l}$ of anhydrous pyridine. Samples were dried and redissolved in 1 $\mathrm{ml}$ of chloroform for chromatographic analysis.

Gas chromatography. Quantification of epicuticular wax components in each sample was performed on a Varian 3400 programmable gas chromatograph equipped with a standard flame-ionization detector. The column was a fused silica capillary column (SPB-1, Supelco, Bellfonte, PA) measuring $15 \mathrm{~m}$ by $0.53 \mathrm{~mm}$. A temperature program was run as follows: initial column temperature, $180^{\circ} \mathrm{C}$, increase at $10^{\circ} \mathrm{C} / \mathrm{min}$ to $290^{\circ} \mathrm{C}$, then hold at $290^{\circ} \mathrm{C}$ for $4 \mathrm{~min}$. The injector and detector temperatures were 220 and $320^{\circ} \mathrm{C}$, respectively. Sample volume was $1 \mu \mathrm{l}$ containing $1 \mu \mathrm{g}$ of wax. Variations in injection volumes were accounted for by reporting wax components as a percent of the total injection. Comparisons of wax components among samples were based on retention times (Rt) of known standards verified by GC-mass spectrometry. The experimental design was a randomized complete block and the Pearson's correlation coefficient was generated comparing pooled chemical families to estimates of percent area affected by sooty blotch.

Growth of $P$. fructicola and L. elatius on wax components. Five major epicuticular wax components of the apple cuticle (5)-hexacosanol, lignoceryl-OH, nonacosane, octacosanol, and the triterpenoid ursolic acid-were obtained in pure form (Sigma Chemical Co., St. Louis). Wax components, dissolved in chloroform, were applied to glass cover slips (18 by $18 \mathrm{~mm}$ ), previously washed in chloroform, using an artist's airbrush. The airbrush delivered a thin, even film of wax to the glass in a stream of compressed nitrogen. Treatments consisted of the five waxy components applied individually and a combination of the five. A control was included in which chloroform was sprayed on the coverslips without wax. Coverslips were arranged in the lid of an inverted petri dish. The bottom of the dish was filled with a $0.95 \mathrm{M}$ $\mathrm{NaCl}$ - agar, which maintained the $\mathrm{RH}$ at $97.5 \%$ at $24^{\circ} \mathrm{C}(10,17)$. Coverslips were positioned $3 \mathrm{~mm}$ below the agar surface.

Two isolates each of $P$. fructicola and $L$. elatius were cultured on potato dextrose agar at $24^{\circ} \mathrm{C}$ and $97.5 \% \mathrm{RH}$ in the dark to develop mature conidia which were pregerminated for $24 \mathrm{~h}$ in $0.5 \%$ apple juice. Conidia were rinsed aseptically with water through cheesecloth, then transferred into sterile water. The concentration of the conidial suspension was adjusted with the aid of a hemocytometer to provide 200 conidia in a 2- $\mu$ l drop of the suspension. Nine droplets of inoculum were placed on each coverslip, which was then placed into the petri dish with the salt agar. One coverslip of each of the six wax treatment types and a chloroform control were placed in each petri dish. Each petri dish contained one isolate. There were four replicate petri dishes of each isolate type. 
Dishes were cultured in the dark at $24^{\circ} \mathrm{C}$. Observations for fungal growth were made on a weekly basis for 12 weeks.

Growth of $P$. fructicola and $L$. elatius on wax applied to agar. Wax components were applied on the surface of a minimal agar medium using an airbrush as described above. The minimal medium contained (per liter) consisted of $20 \mathrm{~g}$ of agar, $2 \mathrm{~g}$ of asparagine, $1 \mathrm{~g}$ of $\mathrm{KH}_{2} \mathrm{PO}_{4}, 0.5 \mathrm{~g}$ of $\mathrm{MgSO} \cdot 7 \mathrm{H}_{2} \mathrm{O}, 0.2 \mathrm{mg}$ of $\mathrm{Fe}^{+++}, 0.2 \mathrm{mg}$ of $\mathrm{Zn}^{++}, 0.1 \mathrm{mg}$ of $\mathrm{Mn}^{++}, 5 \mu \mathrm{g}$ of biotin, and $100 \mu \mathrm{g}$ of thiamine. In subsequent tests, water agar ( $25 \mathrm{~g}$ of agar per liter of water) was used without added salts. Wax treatments for all agar-based tests were (i) nonacosane, (ii) ursolic acid, (iii) complete apple wax, and (iv) control (solvent only).

The same four isolates were used and inoculum was prepared as described above. Each isolate of $P$. fructicola and $L$. elatius was included in each dish, which contained a single wax treatment. Each treatment was replicated four times. The experimental design was a complete block design with four replications and the experiment was repeated three times. Dishes were incubated at $24^{\circ} \mathrm{C}$ in the dark and growth was estimated by measuring the diameter of colony growth at 7-day intervals. Data were analyzed by the general linear model procedure using SAS (SAS Institute, Inc., Cary, NC).

Growth on wax without agar. This experiment was similar to the previous experiment except no agar base was used and wax components were applied with an artist's airbrush directly onto the lids of sterile, plastic petri dishes. The RH in each dish was maintained at $97.5 \%$, with salt agar suspended over the inoculum, as described previously. Conidia of the two isolates of $P$. fructicola and L. elatius were pregerminated in $0.5 \%$ apple juice. Conidia were divided into two equal portions. One portion was rinsed in sterile water to remove the apple juice. The second portion remained in the apple juice pregermination solution. Concentrations of the conidial suspensions were adjusted with the aid of a hemocytometer to 200 conidia in each $2-\mu \mathrm{l}$ drop of suspension.

Each petri dish contained a single wax treatment and there were four replications per treatment. Each petri dish received four separate inoculum drops, one drop of each of the four isolates. Dishes were incubated at $24^{\circ} \mathrm{C}$ in the dark and growth was determined by measuring colony diameters at 7 day intervals for 21 days. Final determination of growth was made using a microscope equipped with a 0.5-by-0.5$\mathrm{mm}$ ocular grid. Growth was determined in nine squares arranged in an " $X$ " pattern by estimating the percent of the area covered by fungal growth in each square. The experimental design was a split plot, and data were analyzed using the SAS general linear model.

Electron microscopy. At harvest, 15 samples of cuticles were collected from the field, including the outer margins of sooty blotch and flyspeck lesions. Samples, 2 $\mathrm{mm}$ in diameter, were shaved with a scalpel from undisturbed fruit in the field and fixed to metal microscope mounts with two-sided tape. Samples were shaved thin in order to minimize contamination of the microscope with water-filled cells. Samples were air dried over dry $\mathrm{CaSO}_{4}$ for 24 $\mathrm{h}$ before sputter coating with gold-palladium to a layer of $15 \mathrm{~A}$ thick. Micrographs were recorded on type 55 Polaroid film with a Phillips 505 microscope with a spot energy of $10 \mathrm{kV}$.

\section{RESULTS AND DISCUSSION}

Sooty blotch severity in the field was significantly different among cultivars (Table 1). In 1989, Golden Delicious strains (Sundale Spur, Pure Gold, and Lys Golden) were generally more severely affected with sooty blotch (average = $20.8 \%$ surface area) than Red Delicious strains (average $=9.7 \%$ ), but did not always differ statistically. Pure Gold was most severely affected, whereas Oregon II Red Delicious and Starkrimson Red Delicious were the least affected. Flyspeck severity during the same period ranged from 8.6 to $14.0 \%$ of surface area with all the cultivars affected. There was no notable difference in flyspeck severity between Golden Delicious and Red Delicious types. In 1989, sooty blotch incidence was recorded on 15 fruit per replication but not in a manner that could be correlated directly to the composition of the wax components. In 1992, the record keeping was modified with the intent of correlation analysis being performed to compare disease incidence directly to wax composition. 1990 was a very dry year and neither sooty blotch nor flyspeck was observed in the field.

In 1992, the severity of sooty blotch on the five cultivars surveyed was significantly different among cultivars (Table 2) and ranged from 56 to $73 \%$ of fruit surface affected. The most severely affected were Smoothie (71\%) and Coop-17 (73\%). The

Table 1. Sooty blotch, wax weight, and cuticular wax compositional analysis by chemical family of 1989 fruit ${ }^{\mathrm{x}}$

\begin{tabular}{|c|c|c|c|c|c|c|c|c|c|}
\hline \multirow[b]{2}{*}{ Cultivar } & \multirow[b]{2}{*}{ Skin type } & \multirow[b]{2}{*}{ Sooty blotch } & \multirow[b]{2}{*}{ Wax weight ${ }^{y}$} & \multirow[b]{2}{*}{ Ursolic acids $^{\mathrm{z}}$} & \multirow[b]{2}{*}{ n-Alkanes } & \multicolumn{2}{|c|}{ Alcohols } & \multirow[b]{2}{*}{ Aldehydes } & \multirow[b]{2}{*}{ Ketones } \\
\hline & & & & & & Primary & Secondary & & \\
\hline Sundalespur Gold & Yellow & $18.4 \mathrm{~b}$ & $960.7 \mathrm{~ns}$ & $54.3 \mathrm{~b}$ & $36.1 \mathrm{a}$ & $4.4 \mathrm{ab}$ & $3.3 \mathrm{~b}$ & $0.1 \mathrm{~ns}$ & $1.7 \mathrm{~ns}$ \\
\hline Pure Gold & Yellow & $28.6 \mathrm{a}$ & 882.0 & $69.8 \mathrm{a}$ & $18.9 \mathrm{~d}$ & $9.1 \mathrm{a}$ & $1.1 \mathrm{~b}$ & 0.0 & 0.8 \\
\hline Lys Gold & Yellow & $15.5 \mathrm{~b}$ & 915.7 & $66.7 \mathrm{a}$ & $22.6 \mathrm{~cd}$ & $7.7 \mathrm{ab}$ & $1.3 \mathrm{~b}$ & 0.0 & 1.7 \\
\hline Starkspur Supreme & Red & $15.2 \mathrm{~b}$ & 1034.3 & $46.5 \mathrm{c}$ & $29.7 \mathrm{~b}$ & $0.0 \mathrm{~b}$ & $22.6 \mathrm{a}$ & 0.0 & 0.6 \\
\hline Oregon Spur II & Red & $7.9 \mathrm{c}$ & 1038.7 & $47.0 \mathrm{bc}$ & $29.0 \mathrm{~b}$ & $5.4 \mathrm{ab}$ & $17.1 \mathrm{a}$ & 0.7 & 0.0 \\
\hline Starkrimson & Red & $6.0 \mathrm{c}$ & 877.7 & $47.0 \mathrm{bc}$ & $28.8 \mathrm{bc}$ & $0.0 \mathrm{~b}$ & $21.0 \mathrm{a}$ & 0.0 & 1.2 \\
\hline
\end{tabular}

${ }^{x}$ Chemical families are listed in percent of total wax as recorded by gas chromatography. Means followed by the same letter are not significantly different from one another according to the Waller-Duncan mean separation $t$ test; ns = not significantly different.

y Wax mass means represent 45 fruit per cultivar $\left(\mu \mathrm{g} / \mathrm{cm}^{2}\right)$.

z Wax component means represent 15 fruit per cultivar.

Table 2. Sooty blotch, wax weight, and compositional analysis of apple fruit epicuticular wax by chemical family of fruit in $1992^{\mathrm{x}}$

\begin{tabular}{|c|c|c|c|c|c|c|c|c|c|}
\hline \multirow[b]{2}{*}{ Cultivar } & \multirow[b]{2}{*}{ Skin type } & \multirow[b]{2}{*}{ Sooty blotch } & \multirow[b]{2}{*}{ Wax weight ${ }^{\mathbf{y}}$} & \multirow[b]{2}{*}{ Ursolic $\operatorname{acids}^{\mathrm{z}}$} & \multirow[b]{2}{*}{ n-Alkanes } & \multicolumn{2}{|c|}{ Alcohols } & \multirow[b]{2}{*}{ Aldehydes } & \multirow[b]{2}{*}{ Ketones } \\
\hline & & & & & & Primary & Secondary & & \\
\hline COOP17 & Yellow & $73 a$ & $580.1 \mathrm{bc}$ & $38.2 \mathrm{c}$ & $36.5 \mathrm{a}$ & $6.6 \mathrm{bc}$ & $10.5 \mathrm{c}$ & $1.6 \mathrm{~cd}$ & $2.6 \mathrm{~b}$ \\
\hline Liberty & Red & $58 \mathrm{~b}$ & $366.0 \mathrm{~d}$ & $53.8 \mathrm{a}$ & $15.9 \mathrm{~d}$ & $5.7 \mathrm{~cd}$ & $16.0 \mathrm{~b}$ & $3.3 \mathrm{a}$ & $2.9 \mathrm{ab}$ \\
\hline NY65707-19 & Yellow & $57 \mathrm{~b}$ & $610.1 \mathrm{abc}$ & $48.3 \mathrm{~b}$ & $26.2 \mathrm{bc}$ & $7.6 \mathrm{~b}$ & $9.4 \mathrm{c}$ & $2.3 \mathrm{bc}$ & $2.8 \mathrm{ab}$ \\
\hline NY61356-22 & Red & $56 \mathrm{~b}$ & $553.9 \mathrm{c}$ & $32.3 \mathrm{~d}$ & $27.2 \mathrm{bc}$ & $5.0 \mathrm{~d}$ & $26.7 \mathrm{a}$ & $1.9 \mathrm{c}$ & $1.5 \mathrm{c}$ \\
\hline Smoothie & Yellow & $71 \mathrm{a}$ & $586.3 \mathrm{bc}$ & $48.1 \mathrm{~b}$ & $25.0 \mathrm{c}$ & $14.6 \mathrm{a}$ & $5.3 \mathrm{~d}$ & $1.8 \mathrm{c}$ & $3.2 \mathrm{a}$ \\
\hline
\end{tabular}

${ }^{x}$ Chemical families are listed in percent of total wax as recorded by gas chromatography. Means followed by the same letter are not significantly different from one another according to the Waller-Duncan mean separation $t$ test.

y Mean of sooty blotch and wax weight represent 24 fruit per cultivar $\left(\mu \mathrm{g} / \mathrm{cm}^{2}\right)$.

${ }^{\mathrm{z}}$ Wax component mean represents 12 fruit per cultivar. 
severity of sooty blotch was also quite high on Liberty (58\%), NY65707-19 (57\%), and NY61356-22 (56\%). In 1992, no trends were observed regarding sooty blotch severity between Red Delicious and Golden Delicious type cultivars.

Sooty blotch is epiphytic on the fruit surface but, interestingly, sooty blotch will grow on normal fruit cuticles, but was not observed on the russetted surface of fruit. In fact, sooty blotch has been observed growing up to the edge of russet and ending in a sharp line delineating the border. Russett is a suberized surface that is formed in response to the death of the normal epidermal cells. Russett is composed of the same wax components as normal cuticles, but is not permeable to water or leaching nutrients (15). In this study, no colonies of sooty blotch or flyspeck were observed growing in russetted areas either year.

The composition of apple fruit epicuticular waxes varied among cultivars and was consistent in 1989 and 1992 (Tables 1 and 2). Ursolic acid and n-alkanes were the most prominent components. Fewer secondary alcohols were found on Golden Delicious type fruit than on red-skinned apples. Although other wax components differed among cultivars, only secondary alcohol differences distinguished between apples of red or yellow skin color (Tables 1 and 2). In every case, red-skinned fruit had significantly more secondary alcohol content than the yellow skinned cultivars.

Sooty blotch severity and wax composition were correlated positively for ursolic acid ( $r=0.42, P \leq 0.0001)$, primary alcohols $(r=0.60, P \leq 0.0001)$, and ketones $(r$

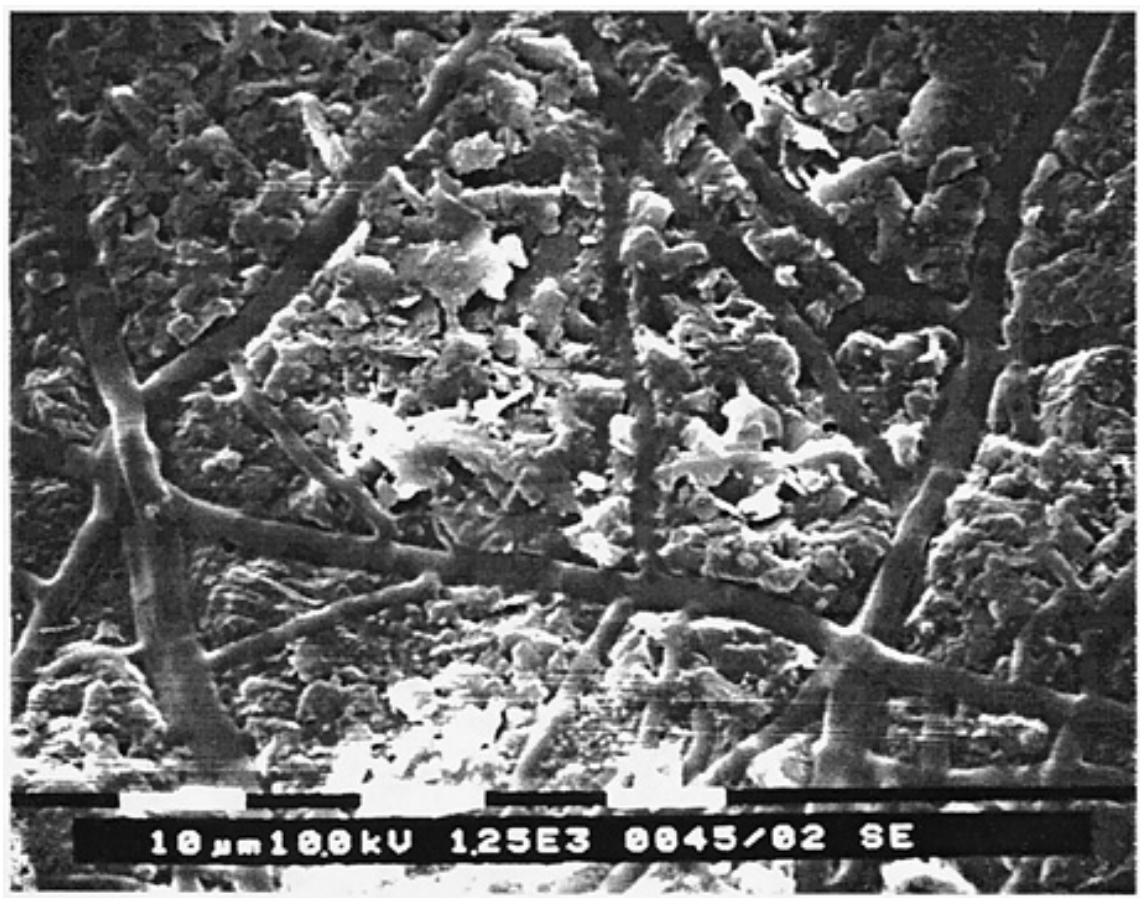

Fig. 1. Scanning electron micrographs of Zygophiala jamaicensis E. Mason (teleomorph, Schizothyrium pomi) on Smoothie Golden Delicious apple. Bar Represents $10 \mu \mathrm{m}$. Epicuticular wax crystals appear dissolved by hyphae.
$=0.58, P \leq 0.0001)$ and sooty blotch severity. A negative correlation was obtained between sooty blotch severity and the secslight negative correlation was obtained between sooty blotch severity and the nalkanes $(r=-0.19, P \leq 0.029)$.

Growth of P. fructicola and L. elatius on coverslips overlaid with the wax components and inoculated with conidial suspensions was sparse, not growing beyond the 0.3 - to $0.4-\mathrm{mm}$ size of the inoculation droplet, and could not be seen without a microscope $(\times 250)$ after 21 days. Based on these results, we concluded that additional nutrients were needed in order to support sufficient fungal growth to determine any preference for the wax components. When waxes were overlaid on minimal medium, growth was vigorous, ranging from 15.8 to treatments, including the control. There was no difference $(P \leq 0.05)$ in growth of either P. fructicola or L. elatius among the wax components overlaid on agar medium. In order to reduce the amount of mycelial growth, we inoculated water agar, without the added nutrients, as a base for the wax treatments in a subsequent experiment. Results were similar to those observed when the minimal nutrient agar was used (15- to $18-\mathrm{mm}$ diameter growth). All four isolates grew vigorously regardless of wax treatment. There was no significant difference $(P \leq 0.05)$ between the wax treatments and the control with no wax when the treatments were overlaid on agar. Thus, there was no clear preference for any of the wax treatments in tests using a minimal ondary alcohols $(r=-0.54, P \leq 0.0001)$. A $18 \mathrm{~mm}$ after 21 days in each of the wax medium or water agar as a base. Isolates grew as vigorously in the controls as on the waxy components; therefore, it was obvious that either our experimental design was not adequate to discriminate among the waxy components or the fungi were unable to utilize wax as a substrate. An additional test was conducted to determine if growth was sustainable on the wax without agar. In a modification of the first experiment, wax treatments were applied on water agar, or to the inside of the lids of petri dishes, without an agar base. Growth of both fungi was vigorous on agar. Again, growth of both fungi on wax alone was sparse and observable only with the aid of a microscope $(\times 250)$.

Growth of $P$. fructicola and $L$. elatius conidia, pregerminated in $0.5 \%$ apple juice and not rinsed, was greatly increased on wax medium without the agar base. Across all wax treatments, including the bare petri dish control, colonies arising from conidia pregerminated in apple juice and not rinsed were significantly larger $(P \leq 0.05)$, covering an estimated $19 \%$ of the test area as compared with conidia pregerminated in apple juice and then rinsed, covering only $9 \%$, or about one half, of the area.

Based on these experiments, it does not appear that the components of the epicuticular wax significantly contribute nutritionally to the growth of either $P$. fructicola and L. elatius on the surface of apple fruit. This conclusion is further supported by comparative SEM observations. In comparison, electron micrographs of flyspeck, Z. jamaicensis, on Smoothie Golden Delicious (Fig. 1) revealed that the hyphae are submerged into the surface of the epicuticular wax. There was a visible void of crystalline wax material, with no evidence of it being simply displaced. These results are similar to those reported by Nasu and Kunoh (26), who suggest that $Z$. jamaicensis metabolizes cuticular wax. In contrast, hyphae of field-collected sooty blotch appear to lie above the wax deposits with no evidence of degradation or absorption of the wax (Fig. 2). These observations imply that sooty blotch and flyspeck hyphae do not interact with cuticular waxes in the same way.

Epicuticular wax does not appear to be a nutritive source for $P$. fructicola and $L$. elatius; therefore, nutrients for their growth must be either externally deposited on the fruit or come from exudation of nutrients. External deposits of substrates are limited by the ability of the surface to accept and retain inoculum and substrate. Adhering substances are more likely to appear on the upper surface of fruit or on the very bottom where droplets collect and evaporate. $P$. fructicola and L. elatius do not appear to have any preference for these areas, as would be expected if external deposits were the source of nutrition. Sooty blotch fungi are known to grow in close association with 20 to 30 plant species (13). If external deposits were responsible for the 
nutritional requirements, it would be possible for growth to occur on any surface on which precipitates could accumulate.

Presence of exudates on the cuticle is dependent on both their internal availability and the permeability of the cuticle. The permeability of the fruit cuticle to water and other substances has been well studied with respect to efficiency of applied crop protection compounds, nutrition, and growth regulators $(2,8,9,28)$. However, information on cuticular permeability of apple fruit exudates is lacking. Kosuge and Hewitt (16) determined that water leached glucose and fructose from grape berries and was responsible for an increase in germination and growth of $B$. cinerea.

Germination of conidia of $P$. fructicola and L. elatius was significantly increased in the presence of $0.5 \%$ apple juice (13). Evidence that sooty blotch does not grow readily on russetted surface that is impermeable to water and presumably nutrients gives further evidence that nutrients leaching to the surface of the fruit act as substrate for sooty blotch growth. Further, the cuticular wax composition may have little or no influence on sooty blotch fungi growth other than as regulators of cuticular permeability.

In summary, sooty blotch severity differed among cultivars, and cuticular waxes also differ among cultivars. Therefore, individual components were tested as substrates or inhibitors of sooty blotch growth. Sooty blotch did not grow when cultured on any of the cuticular components; however, sooty blotch growth did dramatically increase when cultured on agar or cultured

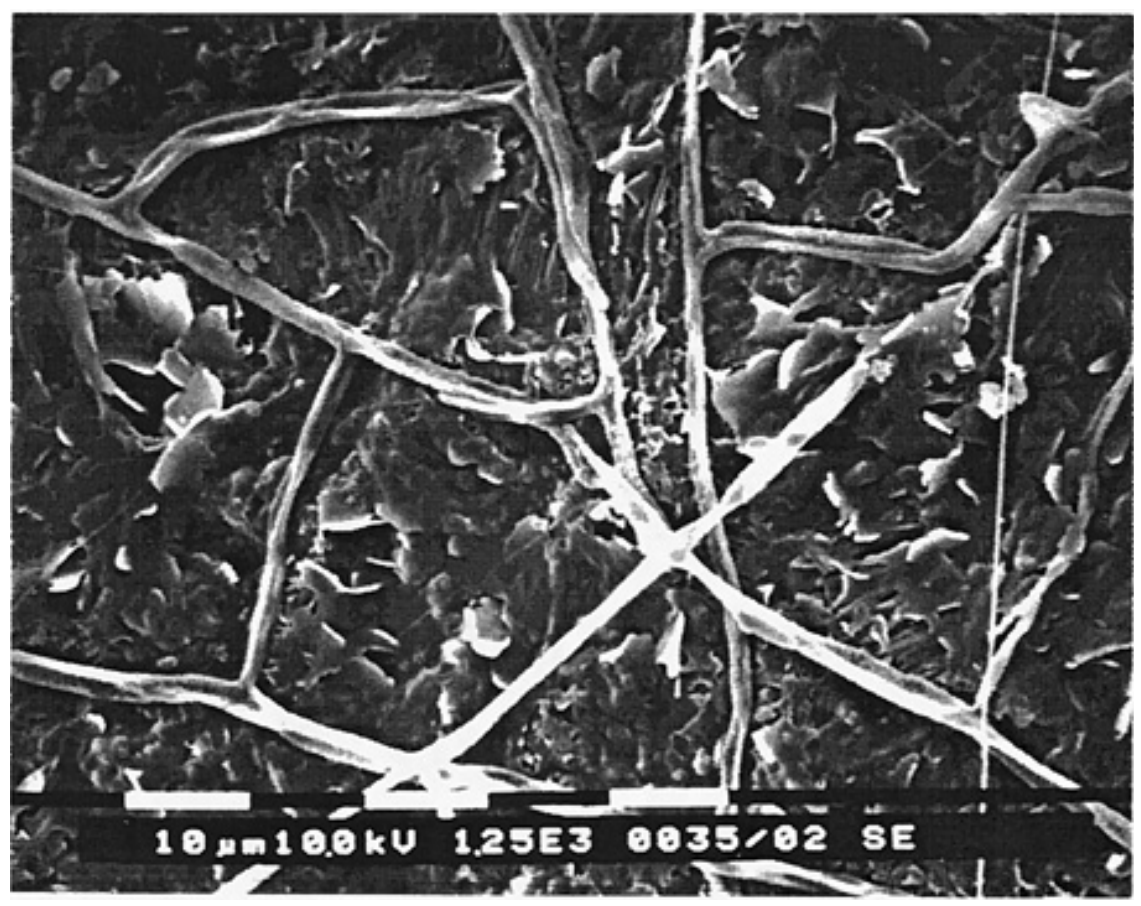

Fig. 2. Scanning electron micrograph Peltaster fructicola grown on Smoothie Golden Delicious apple. Bar represents $10 \mu \mathrm{m}$. Growth is entirely on the wax surface. in the presence of apple juice regardless of wax treatment. Further, sooty blotch was not observed to grow on russetted areas of apple fruit where exudation may be excluded, and sooty blotch only grows on the surface of apples without penetrating the cuticle; therefore, it is reasonable to susblotch growth may be internal fruit carbohydrates escaping to the surface.

Previous works suggest that the cuticular wax has its greatest influence in regulation of cuticular permeability. Therefore, the cuticle could play a role in determining the extent of growth of sooty blotch fungi by its influence on nutrient exudation. Further work needed in this area should concentrate on fruit leachates and the permeability of the cuticle in relation to sooty blotch severity.

\section{LITERATURE CITED}

1. Adams, P. B., Sproston, T., Tietz, H., and Major, R. T.. 1962. Studies on the disease resistance of Ginko biloba. Phytopathology 52:233-236.

2. Baker, E. A., Batt, R. F., Roberts, M. F., and Martin, J. T. 1961. Studies on plant cuticle: progress report. Pages 114-123 in: Annu. Rep. Agric. Hortic. Res. Stn. Bristol., London, England.

3. Baker, E. A., and Hunt, G. M. 1981. Cuticles fruit waxes. New Phytol. 88:732-747.

4. Banks, J. C., and Whitecross, M. J. 1971. Ecotypic variation in Eucalyptus viminalis: leaf surface waxes, a temperature $\times$ origin interaction. Aust. J. Bot. 19:327-334.

5. Belding, R. D. 1996. Epicuticular wax of apple and its relationship to sooty blotch incidence and captan retention. Ph.D. diss, Dep. Hortic. Sci. N. C. State Univ. Raleigh.

6. Blakeman, J. P., and Sztejnberg, A. 1973. Effect of surface wax on inhibition of pect that the substrate necessary for sooty of citrus species. Composition of leaf and germination of Botrytis cinerea spores on beetroot leaves. Physiol. Plant Pathol. 3:269-278.

7. Davies, R. R. 1961. Wettability and capture, carriage, and deposition of particles by raindrops. Nature (Lond.) 191:616.

8. El-Otmani, M., and Coggins, C. W.. 1985 Fruit age and growth regulator effects on the quantity and structure of the epicuticular wax of Washington navel orange fruit. J. Am. Soc. Hortic. Sci. 110:371-378.

9. Flore, J. A., and Bukovac, M. J. 1978. Pesticide effects on the plant cuticle: EPTC effects on the qualitative composition of Brassica oleracea L. J. Am. Soc. Hortic. Sci. 103:297 301.

10. Harris, R. F., Gardner, W. R., Adebayo, A. A and Sommers, L. E. 1970. Agar dish isopiestic equilibration method for controlling the water potential of solid substrates. Appl. Microbiol. 19:536-537.

11. Heather, W. A. 1967. Leaf characteristics of Eucalyptus bicostata Maiden ET AL. seedlings affecting the deposition and germination of spores of Phaeoseptoria eucalypti (Hansf.) Walker. Aust. J. Biol. Sci. 20:11551160.

12. Jeffree, C. E., Baker, E. A., and Holloway, P. J. 1975. Ultrastructure and recrystallization of plant epicuticular waxes. New Phytol. 75:539549.

13. Johnson, E. M. 1994. Etiology of apple sooty blotch disease and temperature and relative humidity effects on development of the fungi in the associated complex. Ph.D. thesis, N. C. State Univ. Raleigh.

14. Johnston, H. W., and Sproston, T., Jr. 1965 The inhibition of fungus infection pegs in Ginko biloba. Phytopathology 55:225-227.

15. Kolattukudy, P. E. 1980. Biopolyester membranes of plants: cutin and suberin. Science 208:990-1000

16. Kosuge, T., and Hewett, W. B. 1964. Exudates of grape berries and their effect on germination of conidia of Botrytis cinerea. Phytopathology 54:167-172.

17. Lang, A. R. G. 1967. Osmotic coefficients and water potentials of sodium chloride solutions from 0 to 40 degrees C. Aust. J. Chem. 20:2017-2023.

18. Lawrence, J. F., Iyengar, J. R., and Sun, W. F. 1985. Gas chromatographic patterns of some apple surface wax constituents. J. Chromatogr. 325:299-303.

19. Main, C. E., and Gurtz, S. K., eds. 1988. 1987 Crop losses due to plant diseases and nematodes. N. C. State Univ. Dep. Plant Pathol Spec. Publ. 8

20. Major, R. T., Marchini, P., and Sproston, T. 1960. Isolation from Ginko biloba L. of an inhibitor of fungus growth. J. Biol. Chem. 235:3298-3299.

21. Marois, J., Bledsoe, A. M., Bostock, R. M., and Gubler, W. D. 1987. Effects of surfactant adjuvants on development of Botrytis cinerea on Vitis vinifera berries. (Abstr.) Phytopathology 77:1148-1152.

22. Marois, J., Bledsoe, A. M., and Gubler, W. 1985. Effects of surfactants on epicuticular wax and infection of grape berries by Botrytis cinerea. Phytopathology 75:1329.

23. Martin, J. T., Batt, R. F., and Burchill, R. T. 1957. Fungistatic properties of apple leaf wax. Nature 180:796-797.

24. Martin, J. T., and Juniper, B. E. 1970. The Cuticles of Plants. St. Martin's Press, New York

25. McWhorter, C. G., Paul, R. N., and Barrentine, W. L. 1990. Morphology, development and recrystallization of epicuticular waxes of Johnsongrass (Sorghum helepense). Weed Sci. 38:22-33

26. Nasu, H., and Kunoh, H. 1987. Scanning 
electron microscopy of flyspeck of apple, pear, Japanese persimmon, plum, Chinese quince and pawpaw. Plant Dis. 71:361-364

27. Reed, D. W., and Tukey, J. 1982. Light intensity and temperature effects on epicuticular wax morphology and internal cuticle ultra- structure of carnation and brussel sprouts leaf cuticles. J. Am. Soc. Hortic. Sci. 107:417420.

28. Roy, S., Conway, W. S., Watada, A. E., Sams, C. E., Erbe, E. F., and Wergin, W. P. 1999. Changes in the ultrastructure of the epicu- ticular wax and postharvest calcium uptake in apples. HortScience 34:121-124.

29. Sparks, D., and Yates, I. E. 1991. Pecan cultivar susceptibility to sooty mold related to leaf morphology. J. Am. Soc. Hortic. Sci. 116:6-9. 